5) западное окончание (Терешкинская вершина) Пугачевского свода.

Такое районирование определяется в первую очередь наличием четырех резких градиентных (разломных) зон северо-западного простирания и различным характером сочетаний потенциальных полей в пределах выделенных участков [7]. В целом на рассмотренной части территории Рязано-Саратовского прогиба по гравимагнитным материалам подтверждаются представления о формировании к палеозою структуры, унаследованно развивавшейся по Пачелмскому авлакогену. Однако границы прогиба не совпадают с границами авлакогена. В процессе формирования Рязано-Саратовского прогиба на границе палеозоя и мезозоя по геолого-геофизическим данным [3] происходит активизация тектонических движений со сменой их знака. Начинается формирование новых структурных элементов, заложение инверсионных структур. Так, над РтищевскоБаландинском грабеном в нижнем структурном этаже развиваются Ртищевский и Баландинский валы, а над Аткарским выступом - Аткарская впадина. Возникают и новые контрастные структуры, такие как Чембарско-Петровский грабен (зона дислокаций в районе осевой линии авлакогена). Имеющийся опыт поисков и разведки нефтегазовых месторождений свидетельствует о наличии локальных структур (в частности, в области Аткарской и Сосновской впадин), но с низкими перспективами нефтегазоносности девонских отложений. Изучение ловушек в низах девона, судя по оценкам на Папановской, Глазуновской и других площадях, дало отрицательные результаты, равно как и оценка «молодых» структур преднеогенового формирования.

В плане лицензионной привлекательности можно выделить наименее изученные участки в центральной зоне Рязано-Саратовского прогиба (в области Ртищевско-Баландинских и ЧембарскоПетровских дислокаций) и в пределах Самарского блока, где наблюдается наибольшая возмущенность геопотенциальных полей. Выполненные исследования свидетельствуют о несомненной полезности и необходимости проведения грави- и магнитометрических наблюдений при отработке региональных геофизических профилей.

\section{Библиографический список}

1. Создание государственной сети опорных геофизических профилей. Основные положения Федеральной Программы развития минерально-сырьевой базы РФ на 1994-2000 годы // Геофизический вестн. 1994. Октябрь. C. 4-8.

2. Липилин А.В., Никитин А.А., Черемисина Е.Н. Проблемы комплексной интерпретации геофизических данных по региональным профилям и пути их решения // Геофизика. 2002. № 4. C 3-6.

3. Шебалдин В.П. Тектоника Саратовской области: Саратов, 2008. $40 \mathrm{c}$.

4. Рыскин М.И., Лепилин В.М., Романов В.В. Геофизические основы тектонического районирования платформенных территорий // Геология нефти и газа. 1995. № 3. C. $15-20$.

5. Буш В.А., Бабаяни П.С., Блох Ю.И. и др. Новые данные по глубинному строению Прикаспийского нефтегазоносного бассейна и южной окраине Русской плиты // Геологические и технологические предпосылки расширения ресурсов углеводородного сырья в Европейской части России / Под ред. Д.Л.Федорова. М., 2006. С. 58-65.

6. Андреев Б.А. Геофизические методы в региональной и структурной геологии: М., 1967. 324 с.

7. Рыскин М.И., Волкова Е.Н., Сокулина К.Б. и др. Комплексная интерпретация геофизических данных в зоне сопряжения Воронежской антеклизы с Рязано-Саратовским прогибом // Геофизика. 2009. №6. С. 38-46.

УДК[552.143-022.532+551.761+551,762] [470.44/47+574.14]

\title{
СРАВНИТЕЛЬНЫЙ АНАЛИЗ ТОНКОДИСПЕРСНЫХ КОМПОНЕНТОВ ОСАДКОВ ТРИАСА И ЮРЫ ПРИКАСПИЙСКОГО РЕГИОНА С ЦЕЛЬЮ ВЫЯСНЕНИЯ ПАЛЕОГЕОГРАФИЧЕСКИХ ОБСТАНОВОК
}

\section{Т.Ф. Букина, З.А. Яночкина}

Саратовский государственный университет, НИИ естественных наук, отделение геологии E-mail: bukina_tf@land.ru

Установлены индикаторы седиментогенеза для палеогеографических реконструкций на основе экосистемно-наноструктурного анализа тонкодисперсных осадков. Для оленёкского возраста раннего триаса выявлены признаки первичных пищевых цепей морского бассейна в пределах ландшафтов, считавшихся ранее континентальными. Они отнесены нами к равнинам, периодически заливаемым морем. Осадки эпиконтинентального бассейна с кокколитами и остракодами определены в разрезах среднего триаса. Абиогенные микро-, наноструктуры аллювиальноозёрно-болотных отложений позднего триаса не сохранили следов переработки организмами. Первичные пищевые цепи, свойственные субокеаническим бассейнам с кокколитами, копеподами, фораминиферами, более уверенно определяются с поздней юры.

Ключевые слова: триас, юра, реконструкция палеоландшафтов, обстановки седиментации, морские бассейны, тонкоди- 
сперсные осадки, биогенные и абиогенные микро-, наноструктуры осадков, первичные пищевые цепи биоценозов.

\section{Compaarative Analysis of the Thinly Dispersed Components of the Triassic and Jurassic Sediments from the Caspian Region Aimed at Revelation of the Paleogeografic Settings}

\section{T.F. Bukina, Z.A. Yanochkina}

Indicators of sedimentogenesis have been established for paleogeographic reconstructions based on ecosystem-nanostructural analysis of finely dispersed sediments. The Early Triassic Olenekian sediments have disclosed some features of primary food chains peculiar for marine basins within the landscapes previously regarded as continental ones. Those have been classified as plains periodically flooded by sea. The coccolith- and ostracod-bearing sediments from epicontinental basins have been recorded in the Middle Triassic sections. Abiogenic micro-, nanostructures of the Late Triassic alluviallacustrine-boggy beds have not retained any traces of transformation by organisms. The primary food chains characteristic of suboceanic basins with coccoliths, copepods and foraminifers are more reliably determinable from the Late Jurassic.

Key words: triassic, jurassic, paleolandscape reconstruction, sedimentation settings, marine basins, finely dispersed sediments, sediment biogenic and abiogenic micronanostructures, biocoenoses primary food chains.

Наряду с минеральным составом осадков рассматриваются взаимоотношения тонкодисперсных биогенных и абиогенных компонентов как показатели процессов седиментогенеза в эволюционирующих бассейнах. Полученные материалы позволили по результатам исследования наноструктур, вещественного состава и породообразующих органических остатков проводить реконструкцию палеоландшафтов [1] с целью выполнения крупномасштабного картирования с дробной стратификацией и корреляцией геологических разрезов, осуществлять прогноз распределения и качества горючих сланцев зоны Dorsoplanites panderi верхней юры [2].

При сравнительном изучении тонкодисперсных осадков триаса и поздней юры для палеогеографических реконструкций использованы индикаторы обстановок седиментации, выявленные с помощью экосистемно-наноструктурного анализа рассматриваемых образований. Доказано наличие в структуре биогенных осадков признаков трёх видов первичных пищевых цепей в различных бассейнах: 1) в нормально-морских бассейнах оленёкского возраста раннего триаса с разуплотнёнными кокколитами и личинками голотурий; 2) в эпиконтинентальных морских бассейнах исследованных регионов с кокколитами и остракодами среднего триаса; 3) в субокеанических бассейнах с кокколитами, фораминиферами, копеподами поздней юры фазы Dorsoplanites panderi на востоке Русской плиты, которые сопоставимы с битуминозными отложениями Западной Сибири. Структуры, полученные при их изучении на поляризационном и электронном микроскопах, показаны в фототаблице.

Таким образом, по результатам исследования тонкодисперсных компонентов удалось установить следующее:

1. Рыхлые кокколитовые микро- и наноструктуры (ККМНС) дисперсных компонентов в раннем триасе в оленёкский век стадии трансгрессии, нарушенные деятельностью илоедов (голотурий), являются индикаторами разуплотнения осадков в начале мезозоя. Это проявляется на территории Прикаспийской впадины и в вулканогенно-осадочных образованиях Мангышлака. Кокколиты имеют следы пищевой переработки. Осадки формировались в условиях иловых впадин лагунно-морского бассейна и равнин, временами заливаемых морем.

2. Плотные ККМНС в остракодово-известковых отложениях среднего триаса формировались в бассейнах эпиконтинентального типа, в Прикаспийской впадине. Они имеют следы кальцитизации и доломитизации, на Мангышлаке существенно изменены гидротермальными процессами - от высокотемпературных в анизийском до низкотемпературных в ладинском веке. В результате переработки остракодами и синседиментационными гидротермальными процессами кокколиты утрачивают скульптурные признаки, сохраняя при этом первичные перфорационные отверстия.

3. Абиогенные микро- и наноструктуры глин верхнего триаса, образованных, как выяснилось, в результате переотложения фрагментов кор выветривания преимущественно Уральского происхождения, а также фрагментов гидротермалитов, развитых на территории Мангышлака, по туфам и эффузивам, не имеют следов переработки морскими организмами. Глинистое вещество ассоциирует с углефицированными растительными остатками, что однозначно определяет их формирование в условиях аллювиально-озёрноболотных ландшафтных обстановок.

4. Разнообразные ККМНС наиболее ярко проявлены в отложениях сланценосной толщи верхней юры [2]. Возрастной интервал, отвечающий фазе Dorsoplanites panderi, сопоставим со временем образования первых мелководных впадин в пределах современного Атлантического океана. Многие исследователи считают позднюю юру $[3,4]$ временем образования новых впадин в акваториях Атлантического, Индийского и Северного Ледовитого океанов [5]. Составление палеоландшафтных схем обстановок седиментации триаса и поздней юры по данным экосистемнонаноструктурных исследований позволяет оценить эволюционный характер океанизации бассейнов как на территории Прикаспийского региона, так и в пределах Западной Сибири, где зона panderi сопоставима с баженовской свитой (по своим свойствам и обилию остатков кокколитофорид). В обширных морях индикаторами 


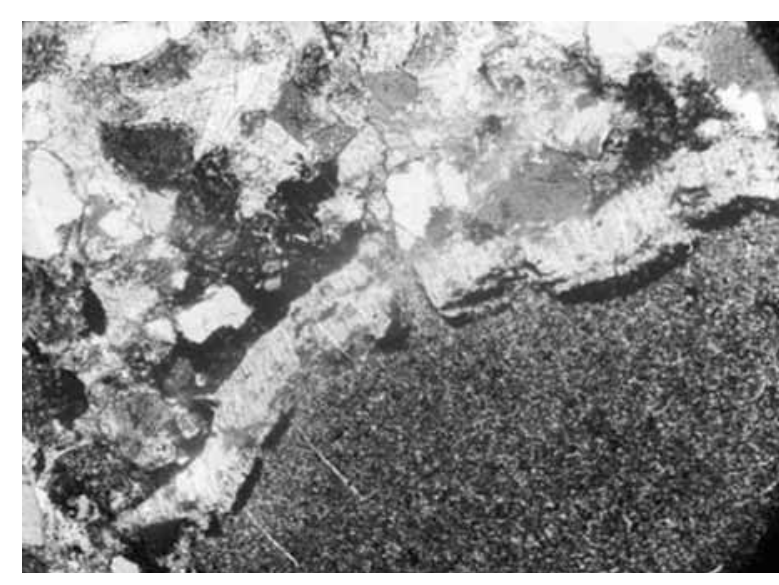

1

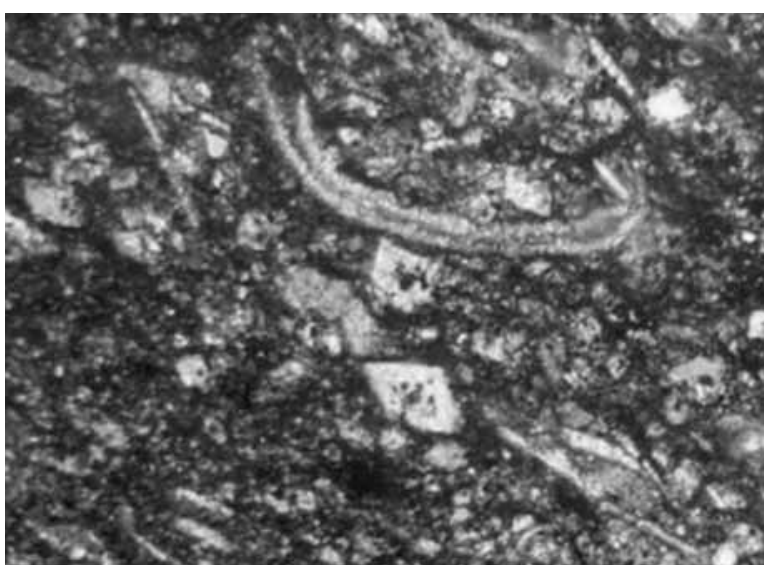

3

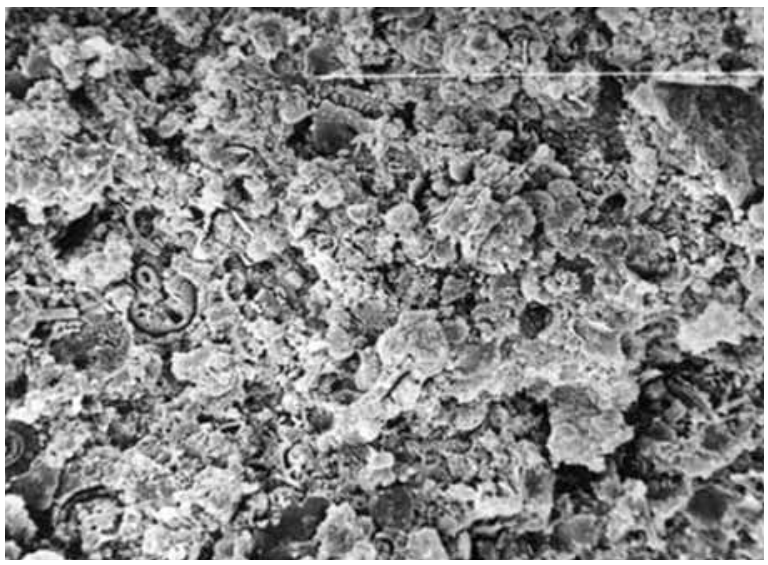

5

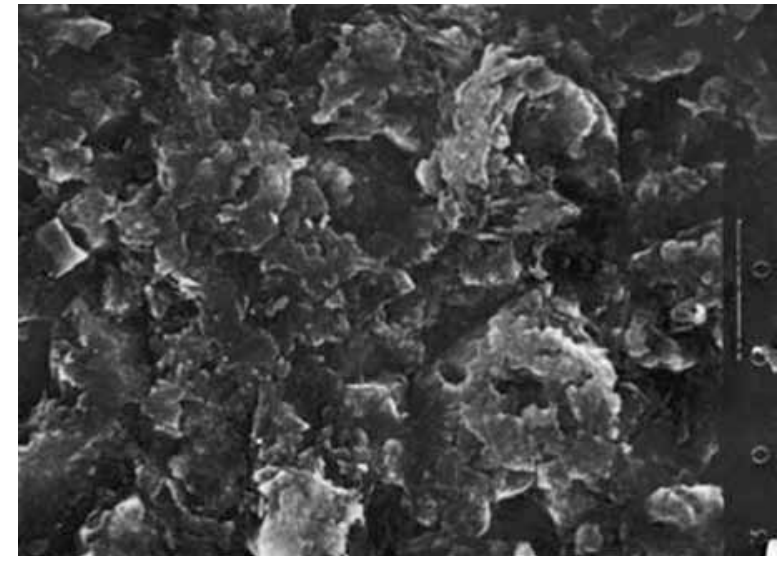

2

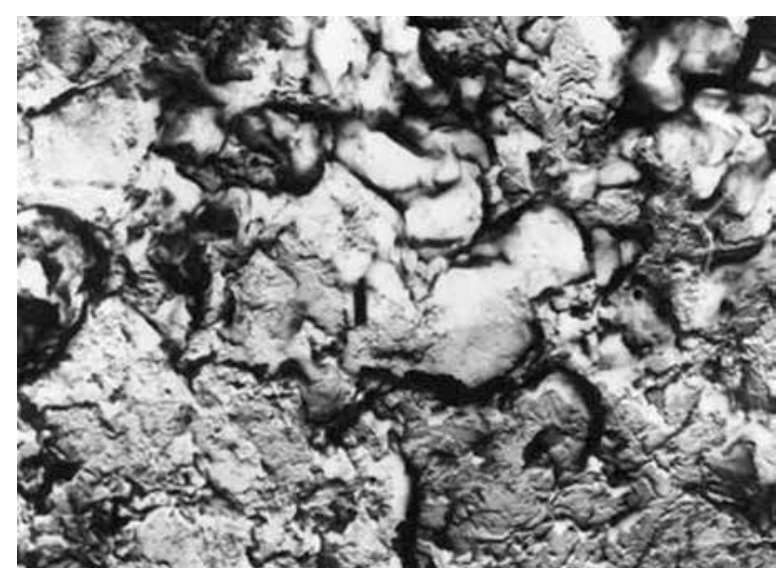

4

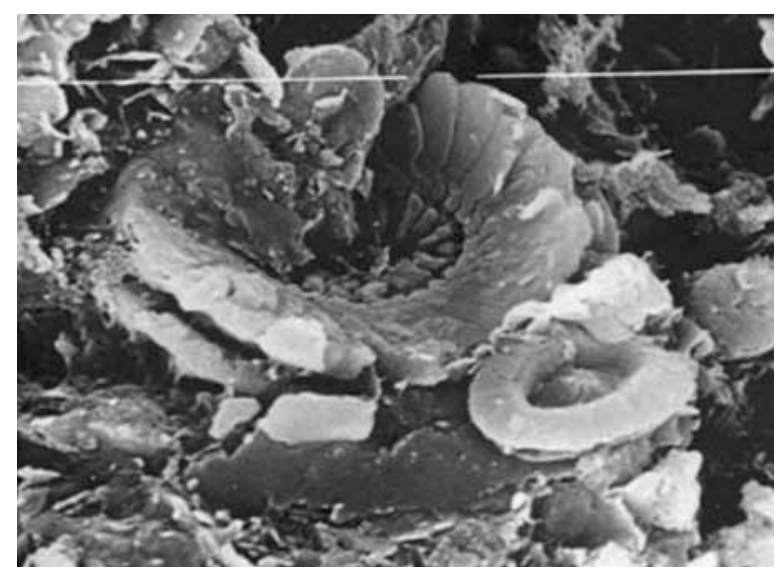

6

Фиг. 1. Фрагмент голотурии с кокколитовым содержимым в песчанике нижнего триаса. Шлиф, увел. 50, поляроиды

Фиг. 2. Рыхлое кокколитовое содержимое голотурии со следами пищевой переработки, РЭМ, увел. 3000

Фиг. 3. Остракодово-кокколитовый доломитизированный известняк среднего триаса. Шлиф, увелич. 300 , поляроиды +

Фиг. 4. Плотное кокколитовое содержимое остракод в известняках среднего триаса. В новообразованных ромбоэдрах доломита форма и перфорационные отверстия кокколитов сохраняются. ПЭМ реплика, увел. 6000

Фиг. 5. Сгустково-комковатое расположение остатков кокколитофорид в горючем сланце высокого качества. (Перелюбское месторождение, верхняя юра, зона Dorsoplanites panderi) РЭМ, увел. 2000

Фиг. 6. Остатки кокколитов хорошей сохранности в горючих сланцах верхней юры зоны Dorsoplanites panderi (Перелюбское месторождение) РЭМ, увел. 9000 
проявления «океанизации», по-видимому, следует считать изменение характера первичных пищевых цепей на микро- и наноуровне. Основными потребителями нанопланктона становятся фораминиферы, копеподы и другие мелкие организмы - типичные обитатели современных океанов, которые являются пищей для более крупных организмов.

Палеоландшафты поздней юры отличаются от позднетриасовых коренным образом. Субокеанический характер первичных пищевых цепей сопровождался распространением во всех акваториях сообществ морских организмов от двустворчатых моллюсков до аммоноидей. и ихтиозавров. На Русской плите шло образование горючих сланцев, а в Западной Сибири - осадков с высокими концентрациями сапропелевого органического вещества «баженовской свиты». По мнению И.В. Хворовой, стагнация бассейнов была обусловлена образованием глубинных порогов широтного простирания, ограничивающих циркуляцию вод океанических впадин.

\section{Библиографический список}

1. Липатова В. В., Жидовинов С. Н., Старожилова Н.Н. $u \partial p$. Информативность методов и критерии расчленения триасовых отложений Мангышлака // Сов. геол. 1984. № 9. C. $49-55$.

2. Кулёва Г.В, Яночкина З.А., Букина Т.Ф. и др. Разрез верхнеюрских сланценосных отложений волжского бассейна (зона Dorsoplanites panderi). Саратов, 2004.

3. Кулон Ж. Разрастание океанического дна и дрейф материков. Л., 1975.

4. Муратов М.В. Происхождение материков и океанических впадин. М., 1975.

5. Рудич E.M. Движущиеся материки и эволюция океанического ложа. М., 1983.

УДК 553.98.2.078

\section{ГИДРОГЕОДИНАМИЧЕСКИЕ УСЛОВИЯ ОСНОВНЫХ НЕФТЕГАЗОВОДОНОСНЫХ КОМПЛЕКСОВ ВОЛГО-УРАЛЬСКОЙ ПРОВИНЦИИ}

\section{М.П. Логинова, К.А. Маврин \\ Саратовский государственный университет, кафедра геологии и геохимии горючих ископаемых E-mail: Loginovamp@info.sgu.ru}

Проведенные исследования показали, что гидрогеодинамические условия основных нефтегазоводоносных комплексов ВолгоУральской провинции являются благоприятными для сохранения залежей углеводородов.

Ключевые слова: гидрогеодинамические условия, нефтегазоводоносные комплексы, сохранность залежей.

\section{Hydrogeodynamic Conditions of the Basic Oil-gas-water- bearing Complexes of the Volga-Ural Province}

\section{M.P. Loginova, K.A. Mavrin}

Leaded researches showed, what hydrogeodynamic conditions of basic oil-gas-water-bearing complexes of Volga-Ural province are favorable for preservation of deposits of hydrocarbons.

Key words: hydrogeodynamic conditions, oil-gas-water-bearing complexes, deposit preservation.

Гидрогеологические (гидрогеодинамические) условия имеют важное значение для формирования, сохранения и разрушения залежей и месторождений нефти и газа.

К гидрогеодинамическим критериям нефтегазоносности относятся показатели процессов водообмена, гидрогеологическая «закрытость» недр, величина пьезометрических напоров, скорость движения подземных вод, распределение пьезомаксимумов и пьезоминимумов и др. [1].

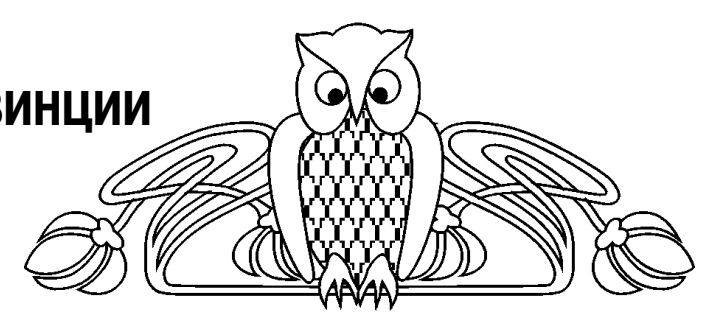

По мнению Н.К. Игнатовича [2, 3], для формирования углеводородных скоплений наиболее благоприятным является такой гидрогеодинамический режим, который при наличии структур и тектонических нарушений на определенном этапе гидрогеологической истории характеризуется активной циркуляцией вод в условиях хорошей закрытости недр.

В зоне свободного водообмена, как правило, не встречаются промышленные залежи нефти и газа, но широко представлены твердые нафтиды, а иногда и жидкие окисленные нефти. Наиболее крупные скопления нефти и газа связаны с зоной затрудненной циркуляции подземных вод. Чем больше мощность зоны активного водообмена и чем ближе расположена подошва этой зоны к кровле фундамента, тем меньше перспективы нефтегазоносности. Нижние гидрогеодинамические зоны, отличающиеся большими мощностями, затрудненным и застойным гидрогеодинамическим режимом, напротив, являются наиболее благоприятными для сохранения залежей углеводородов (УВ). Для них характерна низкая скорость движения подземных вод. Эта закономерность отмечалась для разных территорий А.И. СилинымБикчуриным [4], В.Н. Корценштейном [5], Я.А. Ходжакулиевым [6], Г.П. Якобсоном [7], 